\title{
Factors that Affect Patients' Decision-Making about Mastectomy or Breast Conserving Surgery, and the Psychological Effect of this Choice on Breast Cancer Patients
}

\author{
Mahmut Gumus Basak O. Ustaalioglu Meral Garip Emre Kiziltan Ahmet Bilici \\ Mesut Seker Burcak Erkol Taflan Salepci Alpaslan Mayadagli Nazim S. Turhal
}

Dept. of Medical Oncology, Dr. Lutfi Kirdar Research and Training Hospital, Istanbul, Turkey

Key Words

Breast cancer · Treatment decision · Depression

\section{Summary}

Background: Breast cancer is the most common cancer in women. Primary treatment is surgery, with breast conserving surgery (BCS) being widely used for early-stage disease. Due to changes in body image, depressive symptoms can occur after surgery. Here, we evaluate factors that affect patients' decision on surgery, and investigate differences in the level of depression after mastectomy or BCS in a population of Turkish patients. Patients and Methods: One hundred breast cancer patients who had undergone mastectomy or BCS and were followed up at our institution between 2007 and 2008 were included. Patients were questioned about their involvement in surgical decision-making. Depression was diagnosed according to the Diagnostic and Statistical Manual of Mental Disorders (DSM-III) criteria via a Structural Clinical Interview for DSM (SCID). Severity of depression was evaluated by using the Beck Depression Inventory (BDI). Results: Patients who were older than 50 years, had more than 1 child, a history of lactation, and a positive family history of breast cancer mostly preferred mastectomy. However, patients who sought a second opinion and further information on BCS preferred BCS $(p<0.005)$. There was no statistical correlation between marital status, first childbearing age, and educational status and the decision on surgery type $(p>0.005)$. Mastectomy patients were prone to depression, but this was not statistically significant $(p=0.099)$. Conclusion: Age, parenthood, lactation, and positive familial history, as well as thorough information about the type of surgery were important factors for the patients' decision. After breast cancer surgery, patients might experience depression affecting treatment and quality of life. Therefore, adequate information and communication are essential.
Schlüsselwörter

Brustkrebs · Therapieentscheidung · Depression

\section{Zusammenfassung}

Hintergrund: Brustkrebs ist die häufigste Krebserkrankung der Frau. Die primäre Therapie ist die chirurgische Behandlung, und im früheren Erkrankungsstadium kommt die brusterhaltende Operation (breast conserving surgery, BCS) häufig zum Einsatz. Auf Grund des veränderten Körperbildes kann es zum Auftreten depressiver Symptome nach der Operation kommen. In der vorliegenden Arbeit ermitteln wir Faktoren, die Brustkrebspatientinnen bei der Wahl der chirurgischen Behandlung beeinflussen. Desweiteren werden Unterschiede im Ausmaß der Depression nach Mastektomie bzw. BCS in einer türkischen Patientenpopulation untersucht. Patienten und Methoden: Einhundert Brustkrebspatientinnen, bei denen entweder eine Mastektomie oder BCS durchgeführt wurde, und die zwischen 2007 und 2008 an unserer Institution weiterverfolgt wurden, nahmen an der Studie teil. Die Patientinnen wurden zu ihrer Beteiligung an der Entscheidungsfindung bezüglich der Art der Operation befragt. Depression wurde basierend auf den DSM-III (Diagnostic and Statistical Manual of Mental Disorders)-Kriterien über ein SCID (Structural Clinical Interview for DSM) diagnostiziert. Das Ausmaß der Depression wurde mithilfe des BDI (Beck Depression Inventory) ermittelt. Ergebnisse: Patientinnen, die älter als 50 Jahre waren, mehr als ein Kind hatten, gestillt haben und eine positive Familienanamnese in Bezug auf Brustkrebs aufwiesen, bevorzugten in der Regel eine Mastektomie. Patientinnen, die jedoch eine zweite Meinung und nähere Informationen zu BCS eingeholt hatten, zogen eine BCS vor $(p<0,005)$. Es bestand keine statistische Korrelation zwischen Ehestand, Alter bei Geburt des ersten Kindes, Bildungsstand und der Entscheidung bezüglich der Operationsart $(p>0,005)$. Mastektomie-Patientinnen neigten zu Depressionen, aber dies war statistisch nicht signifikant $(p=0,099)$. Schlussfolgerung: Alter, Elternschaft, Stillen und positive Familienanamnese sowie ausführliche Informationen zum Operationstyp waren wichtige Faktoren bei der Entscheidungsfindung. Brustkrebspatientinnen können an postoperativer Depression leiden, die ihre Therapie und Lebensqualität beeinflusst. Adäquate Information und Kommunikation sind deshalb von großer Wichtigkeit.

\section{KARGER}

Fax +497614520714

Information@Karger.de

www.karger.com (c) 2010 S. Karger GmbH, Freiburg

Accessible online at:

www.karger.com/brc 


\section{Introduction}

Breast cancer is the most commonly diagnosed malignancy in women [1]. Although mastectomy is the standard treatment for breast cancer, breast conserving surgery (BCS) plus radiotherapy is equivalent to mastectomy in terms of survival [1-3]. In 1991, the National Cancer Institute suggested BCS as the preferred surgical treatment for early-stage breast cancer [4]. It was assumed that BCS would largely replace mastectomy, but this has not occurred as currently over one third of early breast cancer patients are treated with mastectomy $[2,5,6]$.

The treatment decision is based on tumor characteristics, the surgeon's experience, and the patient's preference $[1,5]$. If treatment preferences of the patients can be well understood, more effective decision making may be established [1]. A number of studies have investigated the factors that affect patients in their choice of surgery [6-9]. These factors are age, tumor size, placement, socioeconomic factors, race, and marital status. In the literature, it was reported that age and education were important for BCS preference [1, 10]. Also, preference of the surgeon was a major factor influencing the patients' decision making $[1,5]$. One hypothesis stated that inadequately informed patients chose mostly mastectomy [2]. Younger patients had greater concerns about body image and sexuality [5], so age may influence decision-making about breast cancer surgery.

Cancer diagnosis is described as one of the most stressful medical diagnoses a person can receive $[11,12]$. The majority of cancer patients have some degree of depression, and $50 \%$ of this population meet the criteria for a psychiatric diagnosis $[11,13]$. Many patients have psychiatric morbidities, especially anxiety and depressive disorder $[14,15]$. The rate of diagnosis of depression ranges between 6 and $46 \%[11,12,14$, $16,17]$. Psychological distress and anxiety were found to predict overall survival and quality of life in breast cancer patients [18]. Several studies have attempted to evaluate the psychological impact of different surgical treatments on patients with breast cancer $[15,19]$. The psychiatric morbidity associated with mastectomy in the first year of treatment was also reported [19, 20]. Differences about psychosocial outcome between mastectomy and BCS were also previously reported $[16,21]$. Although BCS is considered to be the least disfiguring treatment option, esthetic outcomes vary. The majority of women report breast asymmetry and disfigurement, and failure to adapt to loss of breast tissue. So anxiety and depression are seen after BCS as well as mastectomy [16, 21]. Treatment of depression in breast cancer patients improves quality of life and may increase survival [17]. With an early diagnosis and timely referral to a psychiatrist, patients could have a more comfortable life.

A number of screening instruments has been studied in the oncology setting to improve recognition of depression [22]. In psychiatric research, self-administered scales are frequently used in diagnosing and assessing the severity of depression
[13]. The Beck Depression Inventory (BDI) is a reliable and quick screening instrument and is used worldwide in psychiatric and non-psychiatric patients [13].

In this study, we aimed to detect any differences between mastectomy and BCS in relation to psychological morbidity in a population of Turkish breast cancer patients. At the same time, factors that affect patients' treatment choices between BCS and mastectomy, as well as the psychological impact of such a choice, were investigated.

\section{Patients and Methods}

One hundred women with breast cancer who underwent mastectomy or BCS and were followed up in the Department of Medical Oncology in the Dr. Lutfi Kirdar Research and Education Hospital between December 2007 and March 2008 participated in this study. Eligibility criteria for the study included: confirmed diagnosis of breast cancer, no previous cancer or untreated psychopathology, age between 30 and 80 years, having undergone mastectomy or BCS as breast cancer treatment. All patients were followed up at the outpatient clinic at regular intervals and evaluated retrospectively. Patient histories were taken; demographic factors like age, marital status, having had children, lactation, family history, and operation type were noted. All women provided oral and written informed consent, indicating their awareness of the investigational nature of the study. The demographics form was completed; thereafter patients were given a self-report questionnaire including 33 items relating to the effect of cancer on the patient's mood. In this questionnaire, 7, 14, and 12 items related to anxiety, denial, and depression, respectively. After the patients had answered the questions, responses were scored to detect psychological morbidities in these categories, and compared between the mastectomy and BCS group. Psychiatric symptoms were elicited using a Structural Clinical Interview for DSM (SCID), and classified according to the Diagnostic and Statistical Manual of Mental Disorders (DSM-III) criteria. SCID is the gold standard clinical interview for research diagnosis of depression according to DSM-III criteria [23]. BDI was used to evaluate the severity of symptoms of depression; it was selfadministered and took 5-10 minutes. BDI is composed of 21 items and a quick screening instrument. It is used worldwide in both psychiatric and non-psychiatric patient populations. Beck et al. [13] recommended a score of 10 when screening for mild depression, 16 for mild to moderate depression, 20 for moderate to severe depression, and 30 for severe depression.

\section{Statistical Analysis}

Descriptive statistics were computed for all variables. To explore the relationship between patients' treatment decisions and demographic features, the chi-square test was used. To compare the depression, anxiety, and denial score between the mastectomy and BSC group, the Mann-Whitney U test was used. All statistic analyses were conducted using SPSS 13.0 (SPSS Inc., Chicago, IL, USA), and a p value less than 0.05 was considered as statistically significant.

\section{Results}

Table 1 details the characteristics of the patients. A total of 100 Turkish women with breast cancer were included, modified radical mastectomy was performed in 78 of them, while the others underwent BCS. Approximately $60 \%$ of the pa- 
tients were younger than 50 years of age. Demographic factors that affect the patients' choice of surgery type for breast cancer were evaluated. The patients' age, number of children, lactation history, and second opinion from another surgeon about the surgery type were found to be related to the patients' preferences. Patients younger than 50 years of age were more likely to prefer BCS. The median age of patients who underwent mastectomy or BCS was 40.5 and 49.0 years, respectively. While above $80.0 \%$ of the patients who preferred BCS were younger than 50 years of age, of the patients who underwent mastectomy, $53.8 \%$ were younger than 50 years. So it could be said that older patients mostly preferred mastectomy rather than BCS, and this was statistically signifi-

Table 1. Patient characteristics

\begin{tabular}{|c|c|c|c|}
\hline Characteristics & $\operatorname{BCS}(\mathrm{n}=22)$ & $\operatorname{MRM}(\mathrm{n}=78)$ & $\mathrm{p}$ \\
\hline \multirow[t]{2}{*}{ Age, median (range), years } & $40(30-55)$ & $49(34-70)$ & \\
\hline & \multicolumn{2}{|l|}{ Patients, n (\%) } & \\
\hline Age & & & 0.025 \\
\hline$>50$ years & $4(18.2)$ & $36(46.2)$ & \\
\hline$<50$ years & $18(81.8)$ & $42(53.8)$ & \\
\hline Marital status & & & 1.00 \\
\hline Married & $17(77.3)$ & $59(75.6)$ & \\
\hline Single & $5(22.7)$ & $19(24.4)$ & \\
\hline Childbirth & & & 0.004 \\
\hline Present & $17(77.3)$ & $74(94.9)$ & \\
\hline Absent & $5(22.7)$ & $4(5.1)$ & \\
\hline Lactation & & & 0.007 \\
\hline Present & $16(72.7)$ & $74(94.9)$ & \\
\hline Absent & $6(27.3)$ & $4(5.1)$ & \\
\hline Family history & & & 0.088 \\
\hline Present & $9(40.9)$ & $49(62.8)$ & \\
\hline Absent & $13(59.1)$ & $29(37.2)$ & \\
\hline Education & & & 0.213 \\
\hline High & $10(45.5)$ & $24(30.8)$ & \\
\hline Low & $12(54.5)$ & $54(69.2)$ & \\
\hline Second opinion & & & 0.023 \\
\hline Present & $10(45.4)$ & $15(19.2)$ & \\
\hline Absent & $22(54.6)$ & $63(80.8)$ & \\
\hline
\end{tabular}

MRM = Modified radical mastectomy BCS = breast conservative surgery. cant $(\mathrm{p}=0.025)$. In both groups, mastectomy or BCS, approximately $80.0 \%$ of patients were married. While in the mastectomy group $96 \%$ of patients had one or more children, in the BCS group, this figure was $77.0 \%$. Patients with children wanted a mastectomy rather than BCS, and this was statistically significant $(\mathrm{p}=0.004)$. Like having children, lactation history also had a direct effect on the patients' treatment decision. In our patients, $72.7 \%$ of patients in the BCS group and $94 \%$ of patients in the mastectomy group had a lactation history $(\mathrm{p}=0.007)$. The $25 \%$ of patients who consulted another surgeon preoperatively, mostly preferred BCS ( $\mathrm{p}=0.023)$. Out of the 58 patients with a family history of breast cancer, 49 wanted a mastectomy, although there was no statistically significant correlation $(\mathrm{p}=0.088)$. Factors such as marital status, first childbearing age, and educational status were similar in both groups and did not appear to play a critical role in the decision making process. There was no statistically significant correlation $(p>0.005)$. In addition, we could not find any relation between tumor histopathological type and decision making.

After surgery, 69 and 18 women who had undergone mastectomy and BCS, respectively, had mild depressive symptoms according to BDI, which were not serious enough to warrant psychiatric help. Although there was no significant relation between mastectomy or BCS and depression, patients with mastectomy had more evident depressive symptoms ( $\mathrm{p}=$ 0.099). Also, there was no difference between the anxiety and denial score between the mastectomy and BCS group (table 2). Overall, in this Turkish population, many of the women who had undergone mastectomy seemed to have a poorer quality of emotional life although this was not significant.

\section{Discussion}

Breast cancer is the most commonly diagnosed cancer in women, and as a component of treatment nearly all will face surgery - BCS or mastectomy [3]. In early-stage breast cancer, $\mathrm{BCS}$ is equivalent to mastectomy in terms of survival $[1,2,5]$. In the absence of survival and quality of life differences, the treatment decision can be made according to the patient's preferences [1].
Table 2. Depression anxiety score between $\mathrm{MRM}$ and $\mathrm{BCS}$

\begin{tabular}{llll}
\hline & $\begin{array}{l}\text { BCS, } \\
\text { median (range) }\end{array}$ & $\begin{array}{l}\text { MRM, } \\
\text { median (range) }\end{array}$ & p \\
\hline $\begin{array}{lll}\text { BDI score } \\
\text { SCID }\end{array}$ & $11(0-29)$ & $8(0-42)$ & 0.099 \\
$\quad$ Anxiety score (7 points) & $2(0-6)$ & $2(0-7)$ & 0.293 \\
Depression score (12 points) & $5.5(0-11)$ & $5(0-11)$ & 0.977 \\
Deny score (14 points) & $8(2-13)$ & $9(2-16)$ & 0.356 \\
\hline
\end{tabular}

MRM = Modified radical mastectomy; $\mathrm{BCS}$ = breast conservative surgery; $\mathrm{BDI}=$ Beck Depression Inventory; SCID = Structured Clinical Interview for. 
Studies have shown that as well as clinical factors like tumor size or nodal involvement nonclinical factors like age, socioeconomic status, and race were also important variables in predicting the choice of mastectomy or BCS; younger and married patients and those with higher stages of cancer were shown to be more likely to choose mastectomy [2]. Breast cancer is mostly seen with increasing age [24]. In our study, 22 patients had undergone BCS, and the other 78 had undergone mastectomy. We detected a relationship between age and choice of surgery; in the mastectomy group more than $46 \%$ were older than 50 years while in the BCS group only $18.2 \%$ were above 50 years. Although tumor size was not evaluated in this study, age was an important factor in deciding the type of surgery. Bleicher et al. [9] reported that there was no significant relation between age and surgery type, and two significant predictors of treatment with mastectomy and BCS were degree of patient involvement in decision making and tumor size. Martin et al. [2] also showed that patients with small tumors tended to choose BCS regardless of other factors but patients with large tumors aged over 60 years or younger than 60 years with nodal involvement tended to choose mastectomy. Chagpar et al. [10] found that patients mostly underwent BCS rather than mastectomy; out of 2,762 patients $67.6 \%$ underwent $\mathrm{BCS}$, and the authors agreed that older patients and those with larger tumors and lobular carcinoma type preferred mastectomy due to being less concerned with cosmetic outcome. We did not report tumor type, size, or histopathological properties. Although in previous studies, a higher education level was associated with choosing BCS due to a better understanding of the information regarding recurrence [1], in our study education status was not correlated with the patients' decision on surgery and was similar in both groups. Some patients may inaccurately think that their chance of surviving cancer improves when choosing mastectomy. In the Turkish population, mastectomy is still preferred to BCS. Besides age, patients with more than 1 child and with a lactation history widely preferred mastectomy. Also, patients with a positive family history of breast cancer chose mastectomy more than BCS. This might be influenced by the fact that in our population, women accept that the breast's purpose is lactation rather than being concerned with cosmetic appearance. Patients might think that removing all breast tissue avoids recurrence and disease progression. Therefore, they prefer mastectomy in spite of poor cosmetic outcome.

Psychological distress, anxiety, and depression were found to be common in the range of $1.5-46 \%$ among breast cancer patients, and psychological factors were found to predict quality of life and overall survival in breast cancer $[14,18]$. The breast is considered a symbol of womanhood and sexuality, and having breast cancer or receiving surgical treatment is a traumatic experience for a woman due to its impact on self-image [14]. Previous reports in the literature state that anxiety and depressive symptoms were found during follow- up in women who had a mastectomy. One year after mastectomy, moderate depression was seen in $39 \%$ of patients. The possible loss of femininity and attractiveness, an impaired body image, fear of recurrence, low self-esteem, and poor health are known to cause psychiatric illness [17, 18, 25]. The effect of surgical therapy on psychosocial outcome is controversial [21]. Reich et al. [14] reported that there were no statistically significant differences in body image problems after BCS compared with mastectomy. This might be due to the fact that the rate of radiotherapy after BCS is relatively higher than after mastectomy. Problems with body image are particularly common after breast surgery. Although BCS is considered to be less disfiguring, esthetic outcomes vary widely and patients with more pronounced breast asymmetry are more likely to experience poor psychosocial functioning compared with minimal breast asymmetry [21]. In previous reports, while women with BCS had fewer changes in their body image than those who had undergone a mastectomy, no differences were found in general psychosocial outcome between mastectomy and BCS $[14,16,17,26]$. In one study, Maraste et al. [27] reported that when various age groups were analyzed, there was a significant association between previous mastectomy and morbid anxiety scores in women aged 50-59 years, whereas no discernible association was found in other age groups. However, we did not find any significant differences between surgery type and depression, although mild depression according to BDI was more significant in patients who had undergone mastectomy. The small population size may have played a role.

The variation in prevalence of depression is due to different times of evaluation, usage of different measurements to diagnose depression, and different populations studied [14]. In our study, we used DMS-III criteria to evaluate depression by using SCID, and BDI to evaluate the severity of depressive symptoms. BDI is a screening instrument found to be an accurate self-report measure in oncology $[13,22]$. Beck et al. [13] recommended a score of 10 when screening for mild depression, 16 for mild to moderate depression, 20 for moderate to severe depression, and 30 for severe depression [13, 17, 22].

In conclusion; age, lactation, family history of breast cancer, having had children, marital status, and consultation with a second surgeon were important in the decision making process regarding breast cancer surgery in this Turkish population. The fear of recurrence and non-curative outcome might have outweighed cosmetic appearance in our patients so they mostly chose mastectomy. As a result of our study, we feel that mastectomy did not cause more psychosocial disturbance than BCS.

\section{Conflict of Interest}

There is no actual or potential conflict of interest in relation to this article. 


\section{References}

1 National Cancer Institute: Surveillance Epidemiology and End Results (SEER) Program. SEER Faststats - Breast Cancer, Incidence, 2007. //seer. cancer.gov/faststats.

- 2 Martin MA, Meyricke R, O’Neill T, Roberts S: Simple mastectomy or breast conserving surgery? Factors affecting type of surgical treatment for breast cancer - a classification tree approach. BMC Cancer 2006;6:98

3 Riley GF, Potosky AL, Klabunde CN, Warren JL, Ballard-Barbash R: Stage at diagnosis and treatment patterns among older women with breast cancer: an HMO and fee-for-service comparison. JAMA 1999;281:720-6.

4 Morris CR, Cohen R, Schlag R, Wright WE: Increasing trends in the use of breast-conserving surgery in California. Am J Public Health 2000;90: 281-4.

$\checkmark 5$ Waljee JF, Rogers MA, Alderman AK: Decision aids and breast cancer: do they influence choice for surgery and knowledge of treatment options? J Clin Oncol 2007;25:1067-73.

-6 Molenaar S, Oort F, Sprangers M, Rutgers E, Luiten E, Mulder J, de Haes H: Predictors of patients' choices for breast-conserving therapy or mastectomy: a prospective study. Br J Cancer 2004; 90:2123-30.

$\checkmark 7$ Collins ED, Moore CP, Clay KF, Kearing SA, O'Connor AM, Llewellyn-Thomas HA, Barth RJ Jr, Sepucha KR: Can women with early-stage breast cancer make an informed decision for mastectomy? J Clin Oncol 2009;27:519-25.

8 NIH consensus conference. Treatment of earlystage breast cancer. JAMA 1991;265:391-5.

$\checkmark$ Bleicher RJ, Abrahamsen P, Hawley ST, Katz SJ, Morrow M: The influence of age on the breast surgery decision-making process. Ann Surg Oncol 2008;15:854-62.
10 Chagpar AB, Studts JL, Scoggins CR, Martin RC 2nd, Carlson DJ, Laidley AL, El-Eid SE, McGlothin TQ, Noyes RD, McMasters KM: Factors associated with surgical options for breast carcinoma. Cancer 2006;106:1462-6.

11 Morrow M, White J, Moughan J, Owen J, Pajack T, Sylvester J, Wilson JF, Winchester D: Factors predicting the use of breast-conserving therapy in stage I and II breast carcinoma. J Clin Oncol 2001; 19:2254-62.

12 John D, MacArthur CT: Measures of Depression as a Clinical Disorder. Summary prepared by Sheldon Cohen in collaboration with the Psychosocial Working Group. October 1998.

13 Beck AT, Ward CH, Mendelson M, Mock J, Erbaugh J: An inventory for measuring depression. Arch Gen Psychiatry 1961;4:561-571.

14 Reich M, Lesur A, Perdrizet-Chevallier C: De pression, quality of life and breast cancer: a review of the literature. Breast Cancer Res Treat 2008; 110:9-17.

15 Maguire GP, Lee EG, Bevington DJ, Küchemann CS, Crabtree RJ, Cornell CE: Psychiatric problems in the first year after mastectomy. Br Med J 1978;1:963-5.

16 Holmberg L, Omne-Pontén M, Burns T, Adami HO, Bergström R: Psychosocial adjustment after mastectomy and breast-conserving treatment. Cancer 1989;64:969-74

17 Goldberg JA, Scott RN, Davidson PM, Murray GD, Stallard S, George WD, Maguire GP: Psychological morbidity in the first year after breast surgery. Eur J Surg Oncol 1992;18:327-31.

18 Gandubert C, Carrière I, Escot C, Soulier M, Hermès A, Boulet P, Ritchie K, Chaudieu I: Onset and relapse of psychiatric disorders following early breast cancer: a case-control study. Psychooncology 2009;18:1029-37.
9 Weitzner MA, Meyers CA, Stuebing KK, Saleeba AK: Relationship between quality of life and mood in long-term survivors of breast cancer treated with mastectomy. Support Care Cancer 1997;5:241-8.

20 Meyer L, Aspegren K: Long-term psychological squeal of mastectomy and breast conserving treatment for breast cancer. Acta Oncol 1989;28:13-8.

21 Mystakidou K, Tsilika E, Parpa E, Smyrniotis V, Galanos A, Vlahos L: Beck Depression Inventory: exploring its psychometric properties in a palliative care population of advanced cancer patients. Eur J Cancer Care (Engl) 2007;16:244-50.

22 McArdle JM, George WD, McArdle CS, Smith DC, Moodie AR, Hughson AV, Murray GD: Psychological support for patients undergoing breast cancer surgery: a randomized study. BMJ 1996; 30:813-6.

23 Waljee JF, Hu SE, Ubel AP, Smith DM, Newman LA, Alderman AK: Effect of esthetic outcome after breast-conserving surgery on psychosocial functioning and quality of life. J Clin Oncol 2008;26: 3331-7.

24 Lueboonthavatchai P: Prevalence and psychosocial factors of anxiety and depression in breast cancer patients. J Med Assoc Thai 2007;90:2164-74.

25 Golden-Kreutz DM, Andersen BL: Depressive symptoms after breast cancer surgery: relationships with global, cancer-related, and life event stress. Psychooncology 2004;13:211-20.

26 Levy SM, Herberman RB, Lee JK, Lippman ME, d'Angelo T: Breast conservation versus mastectomy: distress squeal as a function of choice. J Clin Oncol 1989;7:367-75.

27 Maraste R, Brandt L, Olsson H, Ryde-Brandt B: Anxiety and depression in breast cancer patients at start of adjuvant radiotherapy. Relations to age and type of surgery. Acta Oncol 1992;31:641-3. 